\title{
The Research on RTM Molding Process of Thin-wall Rib Structure of Composite Materials
}

\author{
Chao YANª , Kai HE, Yu-Cai SHAN, Cai-Lin LI, Zhi-Jie LIU, Yong-Zhong YANG \\ Chengdu Aircraft Industrial (Group) Co., Ltd., Chengdu, China \\ ac_free@126.com
}

Keywords: RTM, Numerical Simulation, Composite Materials.

\begin{abstract}
The numerical simulation of RIM process is vital for mould design, control of process and parameters optimization and is the important method lowering development costs and ensuring quality. The paper conducts a finite element classification to the rib structure products with $65 \%$ fiber volume and the thickness of $1.5 \mathrm{~mm}$, conducts an emulation calculation to rib products with PAM-RTM software, provides frontier line of resin flowing at different time, calculates gridding and the distribution of pressure field at ending time, determines the positions of glue entering and vent hole and finally conducts a physical verification.
\end{abstract}

\section{Introduction}

Resin matrix composites are more and more widely applied in aerospace filed owing to its advantages of strong designability, antifatigue, corrosion resistance and stable structure size. But the high production costs of resin matrix composites become the biggest bottleneck for its wide application $^{[1]}$. In recent years, automatic tape laying, non-autoclave curing molding and other low-cost production technologies become the important research directions of major aircraft providers $^{[2]}$. And RTM with the features of net size production, no post processing, good accuracy and moulding large components with complex structure becomes one of the low-cost production technologies of resin matrix composite materials world countries race to develop.

RTM moulding is a closing moulding technology in which resin should be fully soaked in order to avoid dry gaps. Optimizing the design, laying and process parameters (injection pressure, temperature and viscosity of resin) of materials in RTM moulding process can effectively shorten the research and development circle of products and lower process complexity ${ }^{[3]}$. The paper adopts RAM-RTM simulation software and chooses different process conditions to conduct a computer emulation simulation to the mold filling process of rib components, optimizes injection hole, materials overflow hole and other tooling parameters and injection pressure, temperature and other process parameters and conducts a physical verification.

\section{Mathematical Model}

The prefabricating process of resin soaked fiber usually uses the transfusion model of porous medium to describe the transfusion process of $\mathrm{F}$ resin in mould cavity. Assuming Darcy law if followed $(1,2)$.

Continuous process: $\nabla * \overrightarrow{\mathrm{V}}=0$

Darcy equation: $\overrightarrow{\mathrm{V}}=-\frac{[K]}{\mu} \nabla \mathrm{P}$

Among the equation, $\overrightarrow{\mathrm{V}}$ is transfusion speed; $\nabla \mathrm{P}$ is pressure gradient; $\mu$ is viscosity of resin; $[\mathrm{K}]$ is tensor of permeability.

After entering equation (2) to equation (1), 
Pressure field equation: $\nabla *\left(\frac{[K]}{\mu} \nabla \mathbf{P}\right)=0$

Boundary conditions are: injection hole $\mathrm{P}=\mathrm{P}_{0}$ (injection under normal pressure), $\overrightarrow{\mathrm{V}}=\overrightarrow{\mathrm{V}_{0}}$ (injection at normal flow rate), mould surface: $\frac{\mathrm{dP}}{\mathrm{dn}}=0$, flow fronts: $\mathrm{P}=\mathrm{Pamb}$ (ambient pressure) (3).

\section{Geometric Model and Classification of Component}

The paper adopts RAM-RTM and two different glue injection methods to conduct an emulation analysis to rib structure components. Refer to Fig.1 and Fig.2 for the three-dimensional geometrical molding and finite element part.

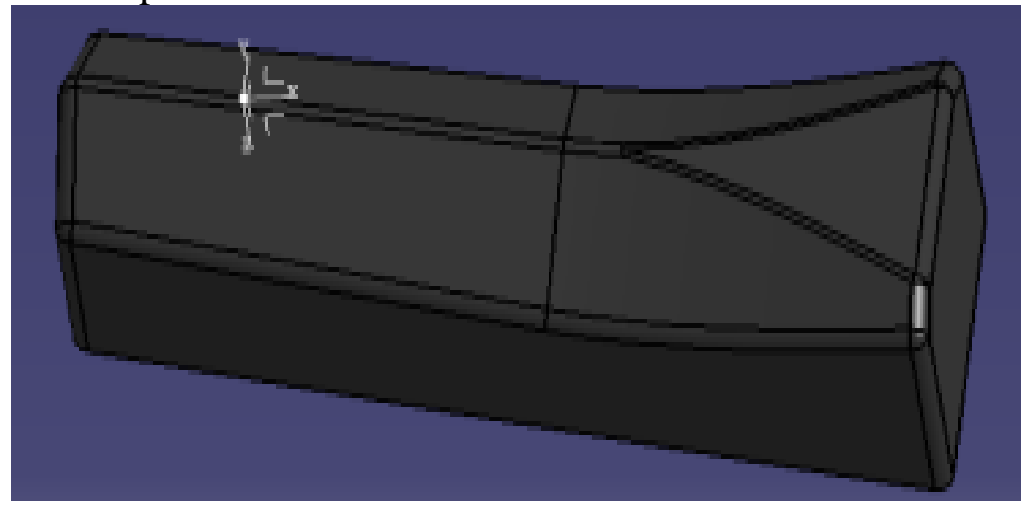

Fig.1 Mathematical Mould of Rib Products
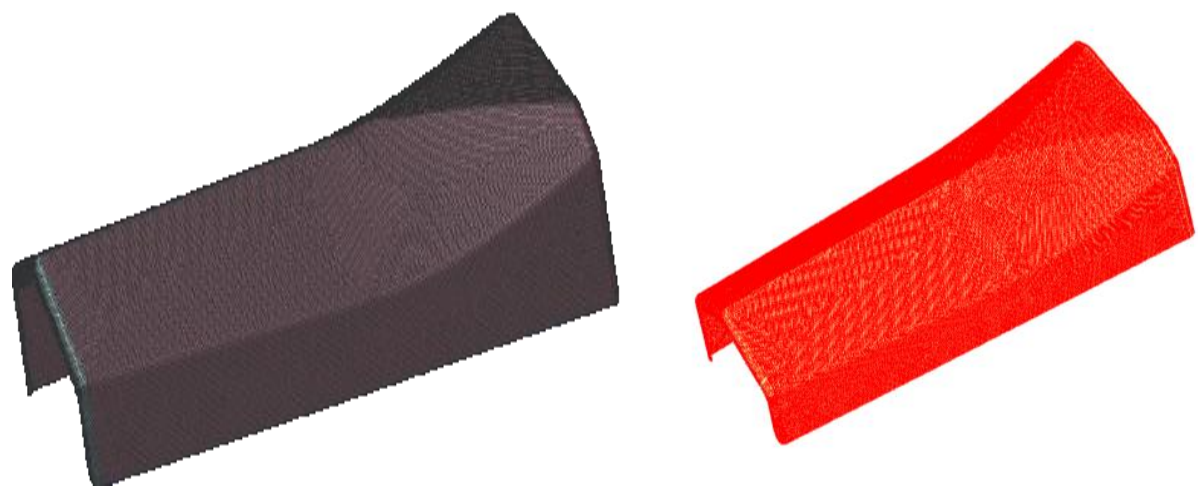

Fig.2 Dividing Gridding

\section{RTM Process Simulation and Verification of Components}

\section{Resin Parameters Measurement}

Respectively refer to Fig.3 and Fig.4 for the rising temperature viscosity curve and constant temperature curve of bismaleimide resin QY8911-IV. According to Fig.3, the viscosity of QY8911-IV is lowest between $100^{\circ} \mathrm{C}$ and $130^{\circ} \mathrm{C}$, namely $0.4 \mathrm{PaS}$; Fig.4 shows the change law of viscosity at $90^{\circ} \mathrm{C}, 100^{\circ} \mathrm{C}, 125^{\circ} \mathrm{C}$ and $135^{\circ} \mathrm{C}$. And its viscosity is lower than $1.0 \mathrm{~Pa} \mathrm{~S}$ at $120 \mathrm{~min}$, $120 \mathrm{~min}, 60 \mathrm{~min}$ and $50 \mathrm{~min}$. And at $125^{\circ} \mathrm{C}$ and $135^{\circ} \mathrm{C}$, when viscosity of resin is higher than $1.0 \mathrm{~Pa} \mathrm{~S}$, viscosity of resin increases rapidly. Therefore, the best temperature is set as $100^{\circ} \mathrm{C}$ in parameters measurement. 


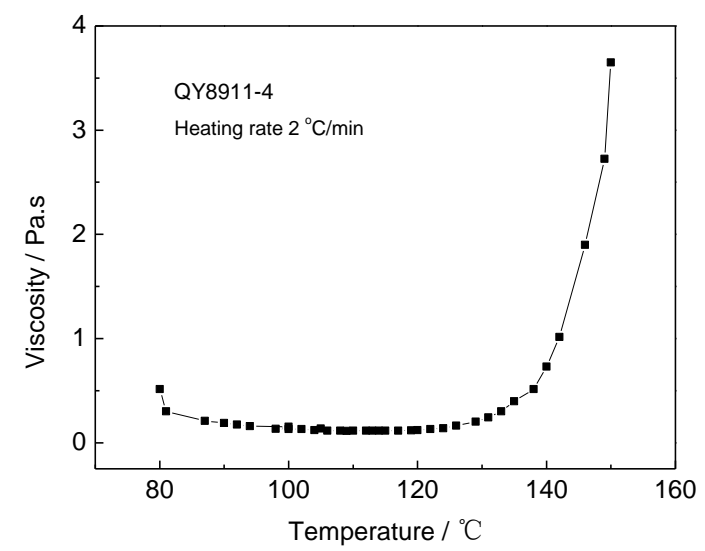

Fig.3 QY8911-IV Rising Temperature Viscosity Curve

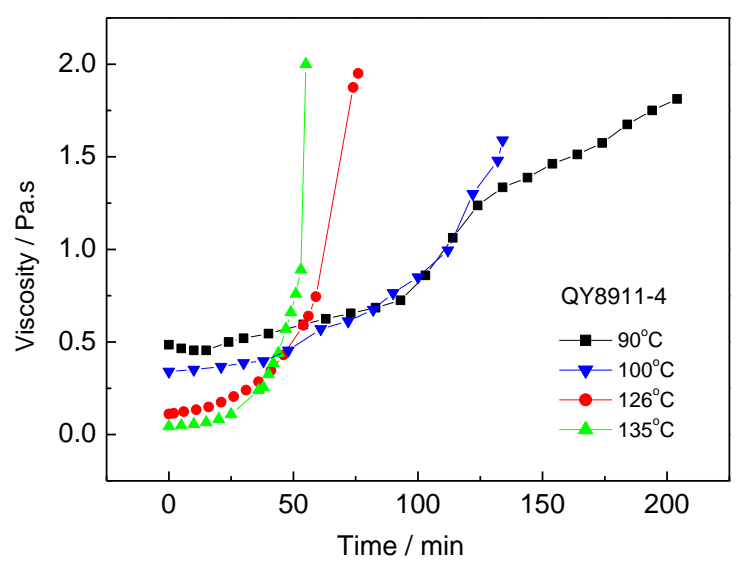

Fig.4 QY8911-IV Constant Temperature Viscosity Curve

\section{Design of Laying Layer}

Fiber adopts T700 class $12 \mathrm{~K}$ unidirectional tyre fabrics U7192 with the surface density of $198 \mathrm{~g} / \mathrm{m} 2$ and the laying layer of [45/90/-45/0]2. The designed volume of laying layer fiber is about $65 \%$.

Different Glue Injection Process Simulation. According to the features of glue injection process, two glue injection methods are designed including one end for glue injection and the other end for glue discharging; the second one is glue injection from the middle and discharging glue from two ends. The specific structure is as follows:

The first glue injection way is to inject glue at one site and discharge glue at the other site at length direction with the fiber volume content of 65\%. RAM-RTM are adopted to simulate the mould filling time of rib products, shown in Fig.5. According to Fig.5, when injecting glue from the left end, the mould filling time of resin is $708 \mathrm{~s}$.
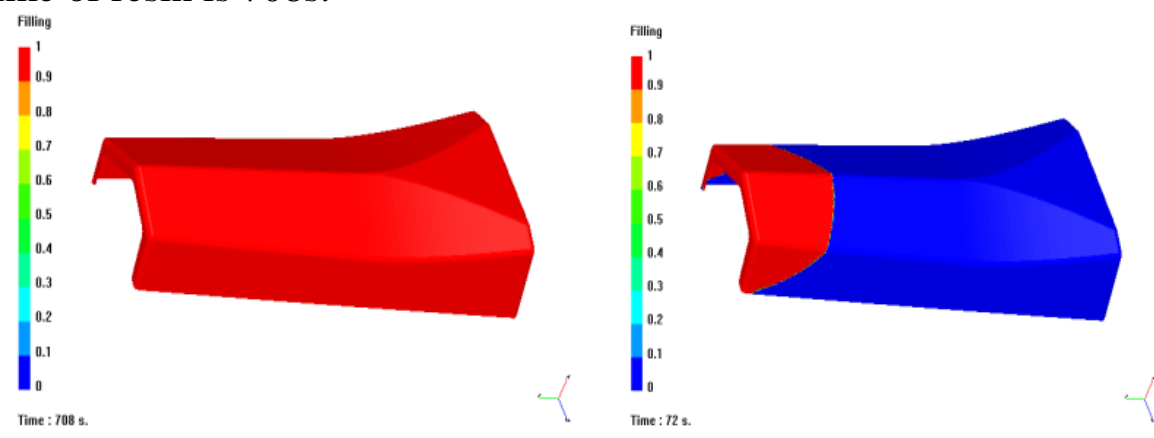

Fig.5 Moulding Filling Process of Resin in the End Glue Injection of Rib Products 
PAM-RTM are adopted to simulate the mould filling pressure process of rib products, shown in Fig.6. According to Fig.6, resin pressure equally decreases along the direction of length.

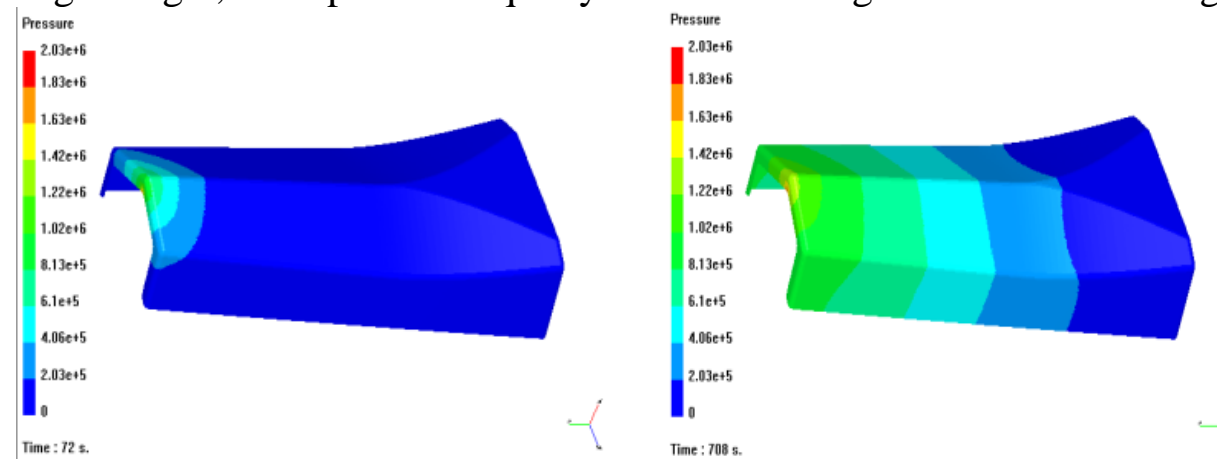

Fig.6 Mould Filling Pressure Distribution of Resin at the Ends of Rib Products

The second glue injection way is shown in Fig.7. After injecting glue in the middle of products, glue flows toward the two ends to fill the mould with the mould filling time of 580s.
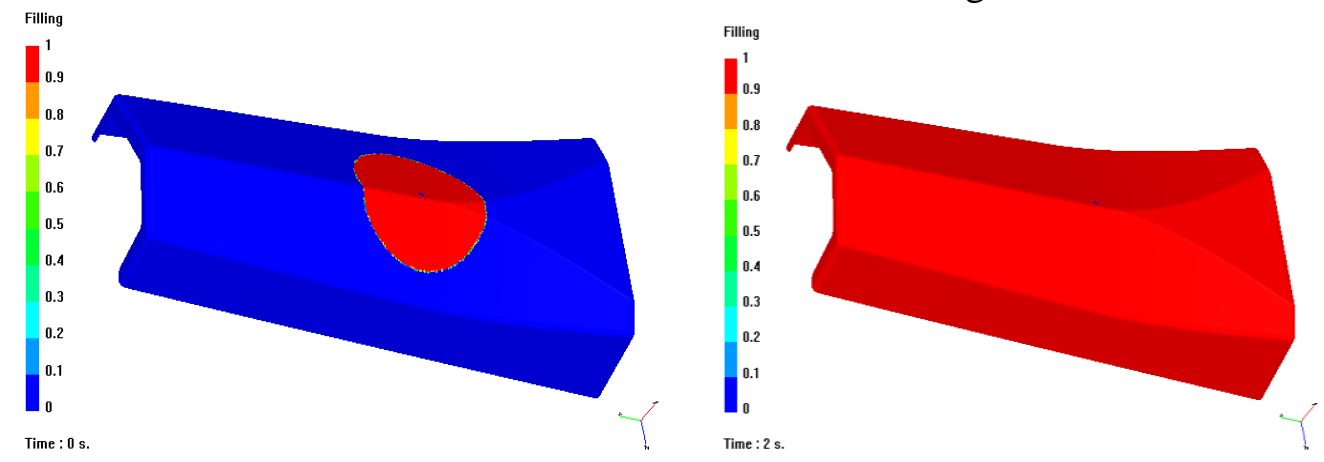

Fig.7 Mould Filling Process of Glue Injected Resin in the Middle of Rib Products
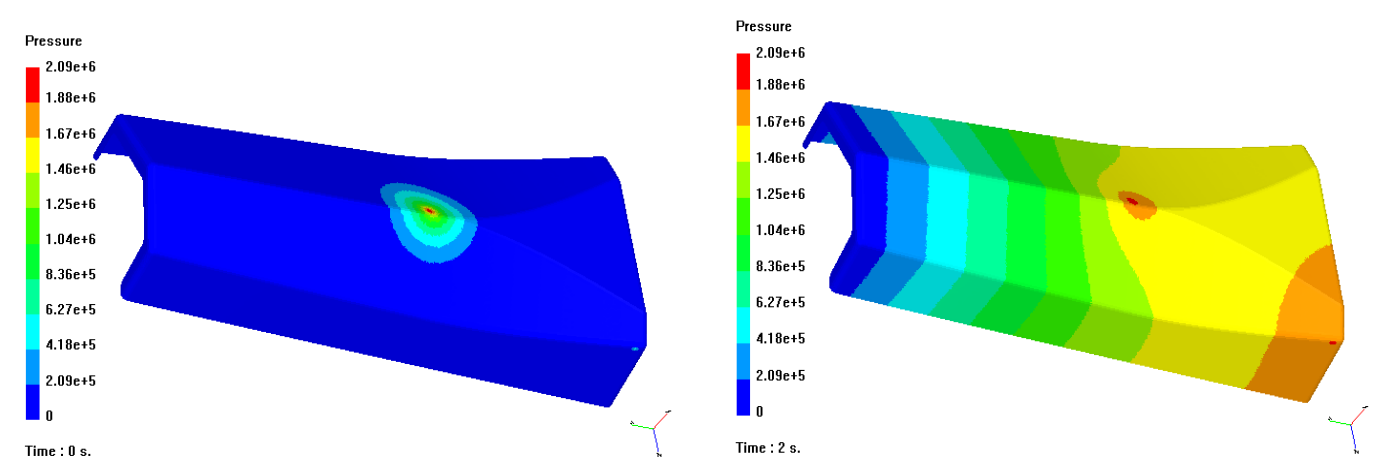

Fig.8 Mould Filling Pressure Distribution of Resin at the Ends of Rib Products

Because the fiber at the profile area of final products will deform if glue is injected from the middle, the method of injecting glue at one end and discharging glue at the other end is adopted.

\section{Experimental Verification}

\section{Manufacturing of Components}

According to emulation effects, rib structure RTM mould is designed, which adopts Yin-yang mould structure with convex mould as the whole structure and concave mould as the sectioning structure; according to the designed laying layer [45/90/-45/0]2, enhanced materials adopt T700 class fiber U7192 and prefabricated parts are laid on convex mould, as shown in Fig.9. 


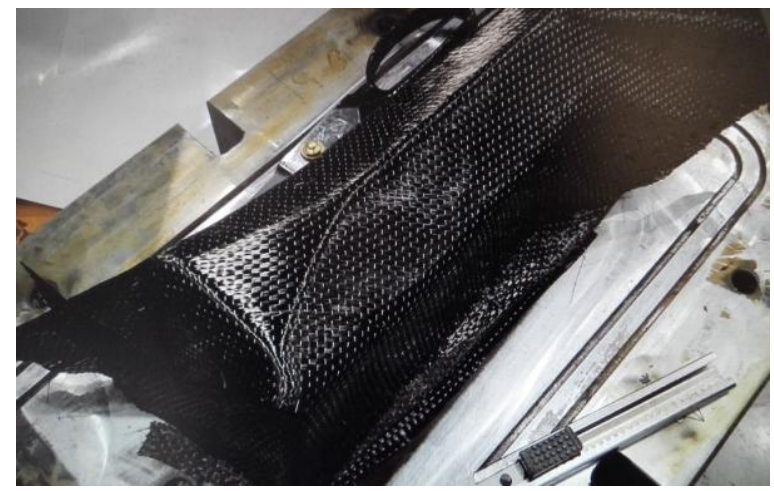

Fig.9 Manufacturing of Prefabricated Parts

\section{Verification of Glue Injection Process}

Glue injection from the middle and injecting glue at one end and discharging glue at the other end are respectively adopted. When injection glue pressure is $2 \mathrm{bar}$, constant pressure glue injection process is adopted to trial-produce 5 products with injection glue time seen in Fig.1 and Fig.2. According to tables, the deviation between simulation glue injection time and actual glue injection time is within 5\%. And when adopting injecting glue at one end and discharging glue at the other end, the deviation between simulation glue injection time and actual glue injection time is smaller and the accuracy is higher. That means PAM-RTM can effectively and accurately predict the RTM moulding and glue injection time of rib composite materials and glue injection pressure and guide production.

Tab.1 The Comparison of Manufacturing Time of Products of Injecting Glue from the Middle and Discharging Glue at the Two Ends

\begin{tabular}{cccccc}
\hline $\begin{array}{c}\text { Serial } \\
\text { number }\end{array}$ & $\begin{array}{c}\text { Simulation } \\
\text { pressure }\end{array}$ & $\begin{array}{c}\text { Actual } \\
\text { pressure }\end{array}$ & $\begin{array}{c}\text { Simulation } \\
\text { time }(\mathrm{s})\end{array}$ & $\begin{array}{c}\text { Actual glue injection } \\
\text { time }(\mathrm{s})\end{array}$ & Deviation \\
\hline 1 & 2 bar & 2 bar & 580 & 550 & $-5.1 \%$ \\
2 & 2 bar & 2 bar & 580 & 570 & $-1.7 \%$ \\
3 & 2 bar & 2 bar & 580 & 600 & $+3.4 \%$ \\
4 & 2 bar & 2 bar & 580 & 560 & $-3.4 \%$ \\
5 & 2 bar & 2 bar & 580 & 605 & $+4.3 \%$ \\
\hline
\end{tabular}

Tab.2 The Comparison of Manufacturing Time of Products of Injecting Glue at One End and Discharging Glue at the Other End

\begin{tabular}{cccccc}
\hline $\begin{array}{c}\text { Serial } \\
\text { number }\end{array}$ & $\begin{array}{c}\text { Simulation } \\
\text { pressure }\end{array}$ & $\begin{array}{c}\text { Actual } \\
\text { pressure }\end{array}$ & $\begin{array}{c}\text { Simulation } \\
\text { time }(\mathrm{s})\end{array}$ & $\begin{array}{c}\text { Actual glue } \\
\text { injection time(s) }\end{array}$ & Deviation \\
\hline 1 & 2 bar & 2 bar & 708 & 730 & $3.1 \%$ \\
2 & 2 bar & 2 bar & 708 & 680 & $-3.9 \%$ \\
3 & 2 bar & 2 bar & 708 & 720 & $1.7 \%$ \\
4 & 2 bar & 2 bar & 708 & 690 & $-2.5 \%$ \\
5 & 2 bar & 2 bar & 708 & 700 & $1.2 \%$ \\
\hline
\end{tabular}

\section{Product Testing}

As shown in Fig.10, ultrasonic A scanning testing and $\mathrm{C}$ scanning testing are conducted to the products made through the two glue injection methods with testing content including internal quality compactness, no dispersivity and lamination defects. Because when adopting injecting glue from the middle, the profile of products has fiber deformation and other defects which influences the quality of products, so the products should adopt injecting glue at one end and discharging glue at the other end. 

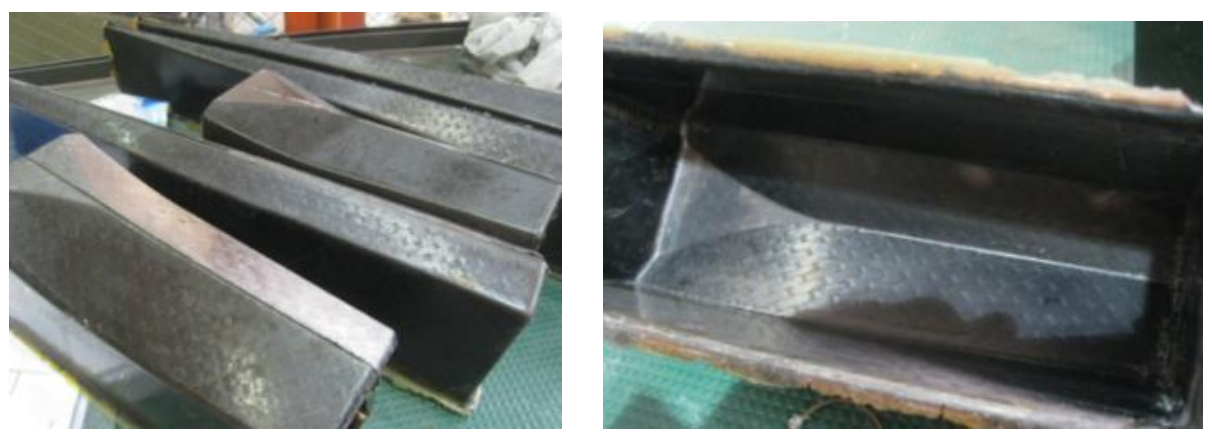

Fig.10 Pictures of Rib Products

\section{Conclusion}

(1) PAM-RTM simulation software can accurately predict the position of glue hole, glue injection time and pressure changes with the accuracy of glue injection time within $\pm 5 \%$.

(2) It is more appropriate for thin-wall rib composite materials to adopt injecting glue at one end and discharging glue at the other end. Though glue injection time is relatively long, it won't lead to fiber deformation and can ensure the surface quality of products better than the method of injecting glue from the middle and discharging glue at two ends.

\section{References}

[1] Maier R S, Rohaly T F, Adbani S G, et al. A fast numertical method for isothermal resin transfer mold filling[J]. International Journal Numerical Methods in Engineering, 1996, 39:1405-1417.

[2] 7-10Dai Fuhong, Zhang Mingbo, Du Shanyi and Wu Zhanjun. Simulation of resin flowing process of injection process of thick-section components, Acta Materiae Composite Sinica, June 7-10th, 2004, Phase III, Volume 21.

[3] Yuexin, Yao Fujun and Zhang Zuoguang, RTM process simulation and dry spot defect control research, Journal of Materials Engineering, 2006: 285-289. 